\title{
Addressing the Stroke Triage Challenge
}

\author{
Rajiv Advani ${ }^{1,2 *}$ \\ ${ }^{1}$ Stroke Unit, Department of Neurology, Oslo University Hospital, Oslo, Norway, ${ }^{2}$ Neuroscience Research Group, Stavanger \\ University Hospital, Stavanger, Norway
}

Keywords: stroke, paramedic (doctor's assistant), triage - emergency service, ambulance, thrombolytic, thrombectomy, education, acute stroke

The treatment of acute ischemic stroke (AIS) has undergone a revolution. More than two decades have passed since the use of intravenous thrombolysis (IVT) was approved for use within $4.5 \mathrm{~h}$ of symptom onset (1). The phrase "Save a minute, save a day" has been used to describe the profound effect of time savings where IVT is administered (2).

Newer works have shown that IVT can also be effective in selected patients up to $9 \mathrm{~h}$ after the onset of symptoms (3).

More severe ischemic strokes caused by a large vessel occlusion (LVO) are associated with significantly higher morbidity and mortality rates. Successful Mechanical Thrombectomy (MT) for LVO stroke within $6 \mathrm{~h}$ has a number needed to treat (NNT) for an improvement in clinical outcome as low as 2.6 (4). Based on newer trials in 2015 the time frame for MT in patients with a LVO stroke was expanded to $8 \mathrm{~h}$ from symptom onset (5). Later the same year, this time frame was expanded to $12 \mathrm{~h} \mathrm{(6).} \mathrm{The} \mathrm{latest} \mathrm{in} \mathrm{this} \mathrm{succession} \mathrm{of} \mathrm{MT} \mathrm{trials} \mathrm{has} \mathrm{shown} \mathrm{that} \mathrm{carefully} \mathrm{selected} \mathrm{patients}$ with LVO can benefit from treatment up to $24 \mathrm{~h}$ after symptom onset (7). These randomized controlled trials selected patients using advanced radiological imaging to determine the presence of viable penumbra.

Despite the expansion of the treatment window early treatment is crucial. If the time saving in the setting of IVT wasn't profound enough, saving a minute prior to treatment in the setting of Mechanical Treatment (MT) grants a week of disability free life (8). This time saving has now been quantified and puts even more emphasis on efficacious treatment - "Save a minute, Save a week". In setting of acute stroke treatment every minute counts. The afore mentioned trials have shown that a significant number of patients achieve functional independence (mRS 0-2) $(6,9)$ with the vast majority requiring only modest assistance (mRS $0-3)(10)$. Time to treatment has been shown to be the key factor associated with better clinical outcome in a large metanalysis (10). The clinical outcomes are significant for each individual patient, but also have a greater socioeconomic impact. The annual cost of care owing to residual stroke morbidity is as great as 90,000 USD, whereas patients achieving functional independence have a significantly lower cost of care, around 15,000 USD (11).

This paradigm shift in treatment has led to an increased burden of duty on paramedics and emergency medical services (EMS) worldwide. The focus being firmly placed on rapid triage and transport of these patients to appropriate stoke treatment centers. Traditionally the FAST (Face, Arms, Speech, Time) acronym has been used to detect a suspected stroke (12). FAST, as a prehospital triage tool, has low sensitivity for the detection of a LVO stroke. This has led to the development more specialized stroke triage scales $(13,14)$. The aim of these newer scales has been to more accurately detect LVO stroke and triage patients to centers offering MT, avoiding unnecessary delay at primary treatment centers. Triaging patients with more severe strokes to comprehensive treatment centers where MT can be performed has been shown to be effective (15). A plethora of these pre-hospital triage scales have been developed showing similar accuracy (16). Centers where Emergency Medical Services (EMS) services employ the use of these newer triages scales have shown time savings and clinical benefit for those patients requiring MT (17). 
These newer pre-hospital scales have however only been put into clinical practice at a limited number of pre-hospital services. In addition to a lack utilization of newer pre-hospital triage scales the time window for urgent triage must be addressed. The majority of triage systems used by the EMS in Scandinavia and Europe prioritize acute ischemic stroke symptoms as urgent within $6 \mathrm{~h}$ of symptom onset $(18,19)$. This, based on the AHA/ASA recommendations, is also the case for severity-based triage used across the USA (20).

This shortened time frame excludes patients eligible for rapid reperfusion therapy from 6 to $24 \mathrm{~h}$ of symptom onset; precluding more than $50 \%$ of the therapeutic window (18). Similarly, patients with unknown symptom onset or wake up strokes are also not always triaged as urgent. These patients potentially stand to benefit greatly from reperfusion therapy (21).

Mobile Stroke Units (MSU) are an innovative strategy employed with great success in some countries with improved stroke treatment times and clinical outcomes (22). However, this strategy relies on large ambulances with trained personnel being able to effectively access the patient population (23). Furthermore, the cost-effectiveness of this initiative is yet to be established for more generalized use (24). Ultimately, with or without access to MSU, symptom recognition, and correct EMS triage are paramount.

EMS worldwide should aim to implement advanced triage scales into clinical practice. In recent years paramedics have successfully used more advanced diagnostic scales. Some examples of these scales, amongst many others, include CPSSS (25), RACE (14), and ACT-FAST (26). Their use has been validated in the setting of LVO diagnostics; showing an excellent degree of agreement between doctors and paramedics (26). This

\section{REFERENCES}

1. Hacke W, Kaste M, Bluhmki E, Brozman M, Davalos A, Guidetti D, et al. Thrombolysis with alteplase 3 to 4.5 hours after acute ischemic stroke. N Engl J Med. (2008) 359:1317-29. doi: 10.1056/NEJMoa0804656

2. Meretoja A, Keshtkaran M, Saver JL, Tatlisumak T, Parsons MW, Kaste M, et al. Stroke thrombolysis: save a minute, save a day. Stroke. (2014) 45:1053-8. doi: 10.1161/STROKEAHA.113.002910

3. Ma H, Campbell BCV, Parsons MW, Churilov L, Levi CR, Hsu C, et al. Thrombolysis guided by perfusion imaging up to 9 hours after onset of stroke. N Engl J Med. (2019) 380:1795-803. doi: 10.1056/NEJMoa1813046

4. Goyal M, Menon BK, van Zwam WH, Dippel DW, Mitchell PJ, Demchuk $\mathrm{AM}$, et al. Endovascular thrombectomy after large-vessel ischaemic stroke: a meta-analysis of individual patient data from five randomised trials. Lancet. (2016) 387:1723-31. doi: 10.1016/S0140-6736(16)00 163-X

5. Griessenauer CJ, Schirmer CM. Dawn of an even newer era: mechanical thrombectomy for acute ischemic stroke beyond 6 to 8 hours. World Neurosurg. (2017) 104:968-9. doi: 10.1016/j.wneu.2017.06.102

6. Goyal M, Demchuk AM, Menon BK, Eesa M, Rempel JL, Thornton J, et al. Randomized assessment of rapid endovascular treatment of ischemic stroke. N Engl J Med. (2015) 372:1019-30. doi: 10.1056/NEJMoa14 14905

7. Nogueira RG, Jadhav AP, Haussen DC, Bonafe A, Budzik RF, Bhuva P, et al. Thrombectomy 6 to 24 hours after stroke with a mismatch between deficit and infarct. N Engl J Med. (2018) 378:11-21. doi: 10.1056/NEJMoa17 06442 will not only augment the detection of a suspected stroke, but also help guide the patient to the appropriate treatment center and treatment pathway. The new expanded treatment windows for MT in the setting of LVO stroke should also be implemented into clinical practice. Limiting the urgent triage response to $6 \mathrm{~h}$ significantly limits the therapeutic window for these patients and eventual reperfusion therapy. These two factors in combination warrant an overhauling of current prehospital stroke triage guidelines.

These newer triage routines have the potential to be implemented in emergency departments in small hospitals where comprehensive stroke treatment isn't offered. Patients showing symptoms of LVO stroke based on the use of newer stroke triage scales arriving at hospitals where MT isn't offered could be transferred directly to comprehensive stroke centers. This would mean that a patient needing MT wouldn't need to undergo a primary evaluation at one hospital before being transferred to a nearest comprehensive stroke center, reducing significant delays before recanalization.

Newer triage routines are being implemented too slowly and patients worldwide are being precluded from treatment daily. The mainstay of this implementation should be based on paramedic education and updating of existing triage algorithms. A better understanding of the recent advances in stroke treatment and implementation of newer pre-hospital triage scales could offer potentially life-saving treatment to many more patients.

\section{AUTHOR CONTRIBUTIONS}

The author confirms being the sole contributor of this work and has approved it for publication.

8. Meretoja A, Keshtkaran M, Tatlisumak T, Donnan GA, Churilov L. Endovascular therapy for ischemic stroke: save a minute-save a week. Neurology. (2017) 88:2123-7. doi: 10.1212/WNL.0000000000003981

9. Molina CA, Chamorro A, Rovira A, de Miquel A, Serena J, Roman LS, et al. REVASCAT: a randomized trial of revascularization with SOLITAIRE FR device vs. best medical therapy in the treatment of acute stroke due to anterior circulation large vessel occlusion presenting within eight-hours of symptom onset. Int J Stroke. (2015) 10:619-26. doi: 10.1111/ijs.12157

10. Saver JL, Goyal M, van der Lugt A, Menon BK, Majoie CB, Dippel DW, et al. Time to treatment with endovascular thrombectomy and outcomes from ischemic stroke: a meta-analysis. JAMA. (2016) 316:127988. doi: 10.1001/jama.2016.13647

11. Simpson KN, Simpson AN, Mauldin PD, Palesch YY, Yeatts SD, Kleindorfer $\mathrm{D}$, et al. Observed cost and variations in short term cost-effectiveness of therapy for ischemic stroke in interventional management of stroke (IMS) III. J Am Heart Assoc. (2017) 6:e004513. doi: 10.1161/JAHA.116. 004513

12. Nor AM, McAllister C, Louw SJ, Dyker AG, Davis M, Jenkinson D, et al. Agreement between ambulance paramedic- and physician-recorded neurological signs with Face Arm Speech Test (FAST) in acute stroke patients. Stroke. (2004) 35:1355-9. doi: 10.1161/01.STR.0000128529.63156.c5

13. Zhang Y, Wang LL. [Predictive value of G-FAST score for acute anterior circulation stroke patients with large artery occlusion]. Zhonghua $Y i$ Xue Za Zhi. (2019) 99:2302-7. doi: 10.3760/cma.j.issn.0376-2491.2019. 29.011

14. Perez de la Ossa N, Carrera D, Gorchs M, Querol M, Millan M, Gomis M, et al. Design and validation of a prehospital stroke scale to predict large 
arterial occlusion: the rapid arterial occlusion evaluation scale. Stroke. (2014) 45:87-91. doi: 10.1161/STROKEAHA.113.003071

15. Katz BS, Adeoye O, Sucharew H, Broderick JP, McMullan J, Khatri $P$, et al. Estimated impact of emergency medical service triage of stroke patients on comprehensive stroke centers: an urban populationbased study. Stroke. (2017) 48:2164-70. doi: 10.1161/STROKEAHA.116. 015971

16. Duvekot MHC, Venema E, Rozeman AD, Moudrous W, Vermeij $\mathrm{FH}$, Biekart $\mathrm{M}$, et al. Comparison of eight prehospital stroke scales to detect intracranial large-vessel occlusion in suspected stroke (PRESTO): a prospective observational study. Lancet Neurol. (2021) 20:213-21. doi: 10.1016/S1474-4422(20)30439-7

17. Lima FO, Mont'Alverne FJA, Bandeira D, Nogueira RG. Prehospital assessment of large vessel occlusion strokes: implications for modeling and planning stroke systems of care. Front Neurol. (2019) 10:955. doi: 10.3389/fneur.2019.00955

18. Twomey M, Wallis LA, Thompson ML, Myers JE. The South African triage scale (adult version) provides reliable acuity ratings. Int Emerg Nurs. (2012) 20:142-50. doi: 10.1016/j.ienj.2011.08.002

19. Perez N, Nissen L, Nielsen RF, Petersen P, Biering K. The predictive validity of RETTS-HEV as an acuity triage tool in the emergency department of a Danish Regional Hospital. Eur J Emerg Med. (2016) 23:337. doi: 10.1097/MEJ.0000000000000173

20. Powers WJ, Derdeyn CP, Biller J, Coffey CS, Hoh BL, Jauch EC, et al. 2015 American Heart Association/American Stroke association focused update of the 2013 guidelines for the early management of patients with acute ischemic stroke regarding endovascular treatment: a guideline for healthcare professionals from the American Heart Association/American Stroke Association. Stroke. (2015) 46:3020-35. doi: 10.1161/STR.00000000000 00074
21. Thomalla G, Gerloff C. Treatment concepts for wake-up stroke and stroke with unknown time of symptom onset. Stroke. (2015) 46:270713. doi: 10.1161/STROKEAHA.115.009701

22. Bache KG, Grotta JC. Improving stroke treatment and outcomes with mobile stroke units. JAMA. (2021) 325:441-2. doi: 10.1001/jama.2020.25832

23. Shuaib A, Jeerakathil T, Alberta Mobile Stroke Unit Investigators. The mobile stroke unit and management of acute stroke in rural settings. CMAJ. (2018) 190:E855-8. doi: 10.1503/cmaj.170999

24. Walter S, Grunwald IQ, Helwig SA, Ragoschke-Schumm A, Kettner M, Fousse $\mathrm{M}$, et al. Mobile stroke units - cost-effective or just an expensive hype? Curr Atheroscler Rep. (2018) 20:49. doi: 10.1007/s11883-018-0751-9

25. Katz BS, McMullan JT, Sucharew H, Adeoye O, Broderick JP. Design and validation of a prehospital scale to predict stroke severity: cincinnati prehospital stroke severity scale. Stroke. (2015) 46:1508-12. doi: 10.1161/STROKEAHA.115.008804

26. Zhao H, Pesavento L, Coote S, Rodrigues E, Salvaris P, Smith $\mathrm{K}$, et al. Ambulance clinical triage for acute stroke treatment: paramedic triage algorithm for large vessel occlusion. Stroke. (2018) 49:945-51. doi: 10.1161/STROKEAHA.117.019307

Conflict of Interest: The author declares that the research was conducted in the absence of any commercial or financial relationships that could be construed as a potential conflict of interest.

Copyright (๑) 2021 Advani. This is an open-access article distributed under the terms of the Creative Commons Attribution License (CC BY). The use, distribution or reproduction in other forums is permitted, provided the original author(s) and the copyright owner(s) are credited and that the original publication in this journal is cited, in accordance with accepted academic practice. No use, distribution or reproduction is permitted which does not comply with these terms. 